\title{
Dietary Glutamate: Interactions With the Enteric Nervous System
}

\author{
Guo-Du Wang, ${ }^{1}$ Xi-Yu Wang, ${ }^{1}$ Yun Xia ${ }^{1,2}$ and Jackie D Wood ${ }^{1 *}$ \\ ${ }^{1}$ Department of Physiology and Cell Biology, The Ohio State University Wexner Medical Center, Columbus, Ohio, USA; and ${ }^{2}$ Department of \\ Anesthesiology, The Ohio State University Wexner Medical Center, Columbus, Ohio, USA
}

\section{Background/Aims}

Digestion of dietary protein elevates intraluminal concentrations of glutamate in the small intestine, some of which gain access to the enteric nervous system (ENS). Glutamate, in the central nervous system (CNS), is an excitatory neurotransmitter. A dogma that glutamatergic neurophysiology in the ENS recapitulates CNS glutamatergic function persists. We reassessed the premise that glutamatergic signaling in the ENS recapitulates its neurotransmitter role in the CNS.

\section{Methods}

Pharmacological analysis of actions of receptor agonists and antagonists in concert with immunohistochemical localization of glutamate transporters and receptors was used. Analysis focused on intracellularly-recorded electrical and synaptic behavior of ENS neurons, on stimulation of mucosal secretion by secretomotor neurons in the submucosal plexus and on muscle contractile behavior mediated by musculomotor neurons in the myenteric plexus.

\section{Results}

Immunoreactivity for glutamate was expressed in ENS neurons. ENS neurons expressed immunoreactivity for the EAAC-1 glutamate transporter. Neither L-glutamate nor glutamatergic receptor agonists had excitatory actions on ENS neurons. Metabotropic glutamatergic receptor agonists did not directly stimulate neurogenic mucosal chloride secretion. Neither L-glutamate nor the metabotropic glutamatergic receptor agonist, aminocyclopentane-1,3-dicarboxylic acid (ACPD), changed the mean amplitude of spontaneously occurring contractions in circular or longitudinal strips of intestinal wall from either guinea pig or human small intestinal preparations.

\section{Conclusions}

Early discoveries, for excitatory glutamatergic neurotransmission in the CNS, inspired enthusiasm that investigation in the ENS would yield discoveries recapitulating the CNS glutamatergic story. We found this not to be the case.

\section{(J Neurogastroenterol Motil 2014;20:41-53)}

\section{Key Words}

Intestines; Motility; Proteolysis; Receptors, glutamate; Secretion

Received: August 20, 2013 Revised: October 1, 2013 Accepted: October 3, 2013

(c) This is an Open Access article distributed under the terms of the Creative Commons Attribution Non-Commercial License (http://creativecommons. org/licenses/by-nc/3.0) which permits unrestricted non-commercial use, distribution, and reproduction in any medium, provided the original work is properly cited.

${ }^{*}$ Correspondence: Jackie D Wood, PhD, AGAF

Department of Physiology and Cell Biology, College of Medicine, The Ohio State University, Columbus, Ohio 43210, USA Tel: +1-614-292-5449, Fax: +1-614-292-4888, E-mail: wood.13@osu.edu

Financial support: The work was supported in part by National Institutes of Health (Grant No. NIH 2 R01 DK 037238) and a grant-in-aid from the International Glutamate Technical Committee, a nongovernmental organization funded by industrial producers and users of glutamate in food.

Conflicts of interest: None.

Author contributions: JDW, concept-design implementation, study supervision, analysis and interpretation of data, statistical analysis and drafting of the manuscript; GDW, acquisition of electrophysiological and organ bath data, analysis and interpretation, and manuscript editing; XYW, acquisition of immunohistochemical and organ bath data, and analysis and interpretation; $Y X$, coordination of operating room procedures for acquisition of human surgical specimens, participation in acquisition of electrophysiological and organ bath data, participation in analysis and interpretation of results. 


\section{Introduction}

Neuroscience in the 1980s-1990s experienced an avalanche of ground breaking advancement of concepts related to the pharmacology and classification of receptors for glutamate as an excitatory neurotransmitter in the brain and spinal cord. As interest in glutamate in the central nervous system (CNS) grew and numbers of original papers on glutamatergic neurobiology expanded, enthusiasm for glutamatergic research spread to the enteric nervous system (ENS). Investigators in neurogastroenterology recognized that the findings in the CNS might translate to the ENS (i.e., the brain-in-the-gut) and moved ahead with testing of a premise that glutamatergic signaling in the ENS would be analogous to that in the CNS. ${ }^{1-3}$ Published results of this early work generally supported the premise. Nevertheless, closer scrutiny of accumulated literature reveals major inconsistencies in analysis and interpretation and casts doubt on the validity of application of discoveries in the CNS to a glutamatergic hypothesis for functional ENS integration of behavior of the effector systems in the digestive tract.

Work that was done in the ENS was focused on recognition in the CNS that receptors for glutamate are commonly partitioned into ionotropic glutamate receptors (iGluRs) and metabotropic glutamate receptors (mGluRs). Ionotropic GluRs are glutamate-gated cation channels that are subdivided into N-methyl-D-aspartate (NMDA) receptors for NMDA and non-NMDA receptors for kainate and a-amino-3-hydroxy-5-methyl-4-isoxazole propionic acid (AMPA). ${ }^{4}$ Metabotropic GluR groups comprise a large family of receptors coupled to second messenger systems via GTP binding proteins. The 8 cloned mGluRs (mGluR1-mGluR8) are divided into 3 groups based on their pharmacology, second messenger coupling and sequence homology. Group I mGluRs (mGluR1 and mGluR5) stimulate phosphoinositide hydrolysis in expression systems; whereas, Group II (mGluR2 and mGluR3) and Group III (mGluR4, mGluR6, mGluR7 and mGluR8) mGluRs inhibit adenylylcyclase activity. ${ }^{5}$ In view of acceptance of the ENS as an independent integrative nervous system, it was logical to expect that evidence for similar partitioning of glutamatergic receptors into functional roles would emerge for the synaptic microcircuits of the ENS. Nevertheless, in spite of a diverse array of research, evidence of this nature for the ENS is equivocal owing to inconsistency among investigative outcomes at the levels of individual neurons, glia and at the level of the functional digestive tract.

\section{Materials and Methods}

Mucosal and muscle preparations from guinea pig ileum and human jejunum were used. Male Hartley-Dawley guinea pigs (0.3-0.6 kg) were killed by rapid stunning and immediate exsanguination from the cervical vessels according to procedures reviewed and approved by the Ohio State University Laboratory Animal Care and Use Committee (Protocol 2010A0023: Exp. 2/11/2013). Fresh human preparations were obtained from segments of jejunum discarded during Roux-En-Y gastric bypass surgeries and transferred immediately to the research laboratory. The human protocols were reviewed and approved by the Institutional Review Board of the Ohio State University Office of Research Risks Protection (Protocol 02H0208).

\section{Electrophysiology}

Flat-sheet preparations of myenteric and submucosal plexus $(2.0 \times 1.0 \mathrm{~cm})$ were obtained by routine methods of microdissection. ${ }^{6}$ The preparations were pinned to Sylgard ${ }^{\circledR}$ resin at the bottom of $2 \mathrm{~mL}$ electrophysiological recording chambers. The chambers were perfused at a rate of $10-15 \mathrm{~mL} / \mathrm{min}$ with Krebs solution warmed to $37^{\circ} \mathrm{C}$ and gassed with $95 \% \quad \mathrm{O}_{2} / 5 \%$ $\mathrm{CO}_{2}$ to buffer at $\mathrm{pH}$ 7.3-7.4. The composition of the Krebs solution was (in $\mathrm{mM}$ ) NaCl, $120.9 ; \mathrm{KCl}, 5.9 ; \mathrm{MgCl}_{2}, 1.2$; $\mathrm{NaH}_{2} \mathrm{PO}_{4}, 1.2 ; \mathrm{NaHCO}_{3}, 14.4 ; \mathrm{CaCl}_{2}, 2.5$; and glucose, 11.5 . Transmembrane electrical potentials were recorded with conventional intraneuronal "sharp" microelectrodes. The microelectrodes were filled with $2 \%$ biocytin in $2 \mathrm{M} \mathrm{KCl}$, buffered with $0.05 \mathrm{M}$ Tris at $\mathrm{pH} 7.4$ as described in detail elsewhere. ${ }^{6}$ The preamplifier (M-767; World Precision Instruments, Sarasota, FL, USA) was equipped with bridge circuitry for intraneuronal injection of electrical current. Synaptic potentials were evoked by focal electrical stimulation of interganglionic fiber tracts in the myenteric or submucosal plexus with electrodes made from 20 $\mu \mathrm{m}$ Teflon ${ }^{\mathrm{R}}$-insulated Pt wire connected through stimulus-isolation units (Grass SIN5) to Grass S48 stimulators (Grass Instrument Division, Astro-Med, Inc., Warwick, RI, USA). All data were recorded initially in digital format for later analysis.

\section{Motility}

Strips were cut from the longitudinal or circular axes of guinea pig ileum or human jejunum and connected to isometric tension transducers in tissue bath setups in vitro (AD-Instruments, Colorado Springs, CO, USA). Canonical pharmacological meth- 
ods were used to analyze actions of L-glutamate and glutamatergic receptor agonists and antagonists on contractile behavior of the segments. Studies were done simultaneously in four tissue baths. Analog changes in muscle contractile tension were digitized and stored on hard disks for analysis.

\section{Mucosal Secretion}

This work was designed to address questions related to glutamatergic stimulation of neurogenic mucosal secretion. The objective was to determine if glutamate is able to cross the mucosa and access receptors expressed by secretomotor neurons in the submucosal division of the ENS and to investigate the identity of any glutamatergic receptors involved. This was done by placing L-glutamate on the mucosal or serosal side of full-thickness, flat-sheet preparations in Ussing flux chambers and measuring changes in electrogenic short-circuit current (Isc) as a marker for stimulation of mucosal secretion. Isc is a surrogate marker for movement of chloride across the mucosal epithelium, the direction of which determines $\mathrm{H}_{2} \mathrm{O}$ and electrolyte movement into or out of the intestinal lumen. ${ }^{7}$ Details of the methods are described in detail elsewhere. ${ }^{8}$

Segments of guinea pig ileum between $10 \mathrm{~cm}$ and $20 \mathrm{~cm}$ proximal to the ileocecal junction or human jejunal segments were flushed with ice-cold Krebs solution and opened along the mesenteric border. Four to eight of the flat-sheet preparations were obtained from each animal for mounting in Ussing flux chambers. Fresh preparations for Ussing chamber studies were procured from human small intestine. They were obtained from segments of jejunum discarded during Roux-En-Y gastric bypass surgeries and studied immediately in the laboratory. Composition of the Krebs solution was in $\mathrm{mM}: 120 \mathrm{NaCl}, 6 \mathrm{KCl}$, $2.5 \mathrm{CaCl}_{2}, 1.2 \mathrm{MgCl}_{2}, 1.35 \mathrm{NaH}_{2} \mathrm{PO}_{4}, 14.4 \mathrm{NaHCO}_{3}$ and 11.5 for glucose. The Krebs solution in the Ussing chambers was bubbled with $95 \% \mathrm{O}_{2} / 5 \% \mathrm{CO}_{2}$ and buffered at $\mathrm{pH}$ 7.4.

The Ussing flux chambers were equipped with pairs of $\mathrm{Ag} / \mathrm{AgCl}$ electrodes via Krebs-agar bridges connected to calomel half-cells for measurement of transmural potential difference (PD). A second pair of electrodes was connected to an automated voltage clamp apparatus, which compensated for the solution resistance between the PD-sensing bridges. The flat-sheet preparations were mounted between halves of Ussing chambers, which had a total cross-sectional area of $0.64 \mathrm{~cm}^{2}$ for guinea pig preparations and $1.13 \mathrm{~cm}^{2}$ for human preparations. The tissues were bathed on both sides with $10 \mathrm{~mL}$ of Krebs solution and maintained at $37^{\circ} \mathrm{C}$ by circulation from a temperature controlled water bath. The current necessary to change the transepithelial PD by $2.5 \mathrm{mV}$ was passed periodically to monitor tissue conductance, calculated according to Ohm's law, and used together with responses to carbachol at the end of the experiment for evaluation of tissue viability. Isc was monitored by electronic voltage-clamp amplifiers (DVC-1000; World Precision Instruments). Concentration-response relations were obtained by adding L-glutamate to the serosal or mucosal compartment of the chamber. Glutamate-evoked changes in Isc were calculated as $\Delta \mathrm{Isc}$. Data were normalized to the cross-sectional area of the preparations.

\section{Immunohistochemistry}

Whole-mount immunohistochemistry was done in essentially the same manner as we described elsewhere. ${ }^{9,10}$ Presentation of methods here summarizes and quotes from these papers. Whole-mount preparations were obtained by microdissection from segments of guinea pig small intestine and transferred to a disposable chamber filled with fixative solution containing $4 \%$ formaldehyde and $2 \%$ of a saturated picric acid solution in 0.1

\begin{tabular}{|c|c|c|c|c|}
\hline Antigen & Host & Code & Dilution & Sources \\
\hline Anti-EAAC1 transporter & Goat & AB1520 & $1: 200$ & Millipore-Chemicon \\
\hline Anti-Glu & Rabbit & AB133 & $1: 200$ & Millipore-Chemicon \\
\hline Anti-Glu & Mouse & MAB5304 & $1: 200$ & Millipore-Chemicon \\
\hline Anti-Hu & Mouse & A-21271 & $1: 500$ & Invitrogen \\
\hline Anti-S-100 & Rabbit & S2644 & $1: 200$ & Sigma-Aldrich \\
\hline Mouse IgG & Donkey & $715-505-150$ & $1: 300$ & Jackson \\
\hline Mouse IgG & Donkey & $715-485-150$ & $1: 100$ & Jackson \\
\hline Mouse IgG & Horse & $\mathrm{Cl}-2000$ & $1: 200$ & Vector \\
\hline Rabbit IgG & Donkey & $711-505-152$ & $1: 300$ & Jackson \\
\hline Rabbit IgG & Donkey & $715-485-152$ & $1: 100$ & Jackson \\
\hline Goat IgG & Donkey (Cy3) & $705-165-147$ & $1: 100$ & Jackson \\
\hline Goat IgG & Donkey (FITC) & $705-095-147$ & $1: 100$ & Jackson \\
\hline
\end{tabular}

Figure 1. Codes and sources of primary and secondary antibodies used in immunohistochemical studies. Anti-Hu, anti-human neuronal protein $\mathrm{HuC} / \mathrm{HuD}$; anti-S-100, low molecular weight protein. 
mol $\cdot \mathrm{L}^{-1}$ phosphate buffered saline (PBS). Nonspecific immunological binding was blocked with $10 \%$ normal donkey serum in $0.01 \mathrm{M} \mathrm{PBS}(\mathrm{pH}$ 7.4) for 1 hour at room temperature. The tissues were incubated with the primary antibodies (Fig. 1) diluted in $0.01 \mathrm{~mol} \cdot \mathrm{L}^{-1}$ PBS containing $10 \%$ normal donkey serum, $0.3 \%$ Triton $\mathrm{X}-100$ and $0.05 \%$ sodium azide for 18 hours at room temperature. The tissues were then washed $(3 \times 10 \mathrm{mi}-$ nutes) in PBS ( $\mathrm{pH}$ 7.4) and transferred to an incubation medium that contained a single secondary antibody or a mixture of secondary antibodies (Fig. 1). Combination of primary antibodies for glutamate, glutamate transporter, $\mathrm{S}-100$ protein and $\mathrm{HuC} / \mathrm{HuD}$ was done at the same time to achieve double immunolabeling. After incubation with the antibodies, the tissues incubated with appropriate secondary antibodies were conjugated with fluorescence isothiocyanate (FITC) or indocarbocyanin (Cy3) diluted in $0.01 \mathrm{~mol} \cdot \mathrm{L}^{-1} \mathrm{PBS}$. The tissues were then rinsed in PBS and cover slipped with Vectorshield (Vector, Burlingame, CA, USA). Pre-absorption of the primary antibodies with appropriate antigen was done as controls. Specificity of immunostaining was also checked by omitting either the primary or secondary antibody.

All preparations were examined under a Nikon Eclipse E-600 fluorescence microscope (Nikon Inc., Melville, NY, USA) and analyzed with filter combinations that enabled separate visualization of multiple fluorophores. Digital images were obtained with a SPOT RT cooled CCD digital camera (Diagnostic Instruments, Sterling, Heights, MI, USA), stored on disk, and analyzed with SPOT II software. Contrast in the digital images was sometimes enhanced before either converting to JPEG file interchange format (*.jpg) for electronic transfer or printing as photomicrographs with ink jet printers.
The proportions of neurons that expressed glutamate or glutamate transporter immunoreactivity relative to the total neuronal population in the myenteric and submucosal divisions of the ENS were evaluated by double labeling with a mouse monoclonal antibody for human neuronal protein $\mathrm{HuC} / \mathrm{HuD}$ (anti-Hu) and glutamate. Anti-Hu antibody binds specifically to antigens that are expressed exclusively in neurons and is a useful tool for marking all neurons in the ENS. ${ }^{11}$ Distribution of glutamate-immunoreactivity (IR) in relation to glia was evaluated by double labeling with a rabbit monoclonal antibody for S-100 protein and glutamate. Anti-S-100 antibody binds to astrocyte-like glia and is a useful marker for glia in the ENS. ${ }^{12}$

\section{Reagents and Antibodies}

L-Glutamate, (RS)-3,5-Dihydroxyphenylglycine (RS)-3,5DHPG), (1S,3R)-1-Aminocyclopentane-1,3-dicarboxylic acid (1S,3R)-ACPD), ( \pm )-1-Aminocyclopentane-trans-1,3-dicarboxylic acid (ACPD), (S)-4-Carboxyphenylglycine (CPG), (RS)$\alpha$-Methyl-4-carboxyphenylglycine disodium salt (MCPG), (RS)2-Chloro-5-hydroxyphenylglycine sodium salt (CHPG), (3S)-3[[3-[[4-(Trifluoromethyl)benzoyl] amino $]$ phenyl $]$ methoxy]-Laspartic acid (TBOA), L-Quisqualic acid, and N-Methyl-D-aspartic acid (NMDA) were purchased from Tocris (Ellisville, MO, USA). Tetrodotoxin and ( \pm )-AMPA (2-amino-3-(3-hydroxy5-methyl-isoxazol-4-yl)propanoic acid) were purchased from Sigma-Aldrich Biochemicals (St. Louis, MO, USA). Antibodies and antisera are listed in (Fig. 1).

\section{Statistical Methods}

Results are expressed as mean \pm SEM. Student's $t$ test and
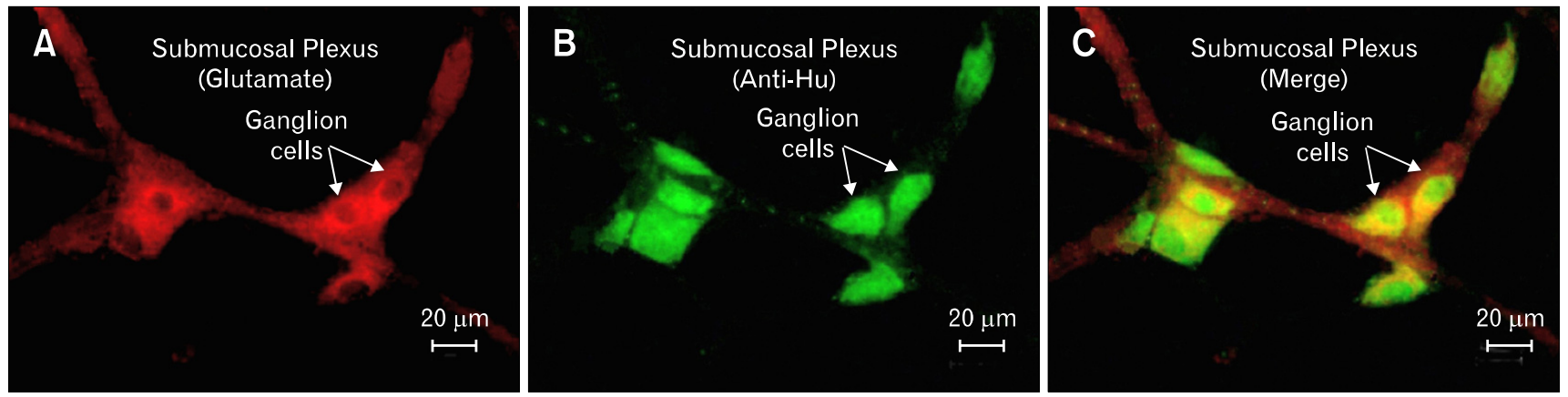

Figure 2. Proportion of neurons expressing glutamate-immunoreactivity (IR) in whole-mount preparations of the submucosal plexus was determined by double-labeling glutamate and anti-human neuronal protein $\mathrm{HuC} / \mathrm{HuD}$ (anti-Hu) in guinea pig small intestine. IR for the neuron-specific RNA binding protein, $\mathrm{Hu}$, was used to assess the total numbers of neurons in the preparations. (A) Expression of glutamate in a whole-mount preparation of the submucosal plexus. (B) Expression of anti-Hu-IR in the same whole-mount as A. (C) Digital merger of A and B revealed co-expression of glutamate-IR and anti-Hu-IR in $63.9 \%$ of the submucosal ganglion cells overall. 
paired $t$ test were used for statistical analysis of significance with $P<0.05$ accepted as significant. Ussing chamber data are presented as means $\pm \mathrm{SE}$ with $\mathrm{n}$ values referring to numbers of patients and preparations. Continuous curves for concentration-response relationships were constructed with the following least-squares fitting routine using Sigmaplot ${ }^{\circledR}$ software (SPSS Inc., Chicago, IL, USA): $V=V_{\max } /\left[1+\left(\mathrm{EC}_{50} / C\right)^{n \mathrm{H}}\right]$, where $V$ is the observed increased $I s c, V_{\max }$ is the maximal response, $C$ is the corresponding drug concentration, $\mathrm{EC}_{50}$ is the concentration that induces the half-maximal response, and $n_{\mathrm{H}}$ is the apparent Hill coefficient.

\section{Results}

\section{Immunohistochemistry}

Nerve cell bodies, expressing glutamate-IR, were present in the myenteric and submucosal plexuses (Fig. 2 and 3). We examined the distribution of glutamate-IR neurons quantitatively by counting the neuronal cell bodies with glutamate-IR and anti-Hu-IR in ganglia in whole-mount preparations from 4 guinea pigs. In myenteric plexus preparations, $57.6 \%$ (157/273) of the neurons expressed glutamate-IR; in the submucosal plexus $63.9 \%(85 / 133)$ of the neurons expressed glutamate-IR.

We used double-labeling immunohistochemistry to compare expression of glutamate-IR and expression of S-100 protein-IR. No significant co-expression of glutamate-IR and S-100 protein-IR was found in whole-mount preparations removed from the myenteric and submucosal plexuses of 4 guinea pigs (Fig. 4).

Immunoreactivity for the EAAC-1 glutamate transporter was co-expressed with the pan neuronal marker, anti-Hu, in $42.7 \%(88 / 206)$ of the nerve cell bodies in the submucosal plexus and $53.5 \%(244 / 456)$ of the nerve cell bodies in the myenteric plexus (Fig. 5 and 6). Immunoreactivity for the EAAC-1 gluta-
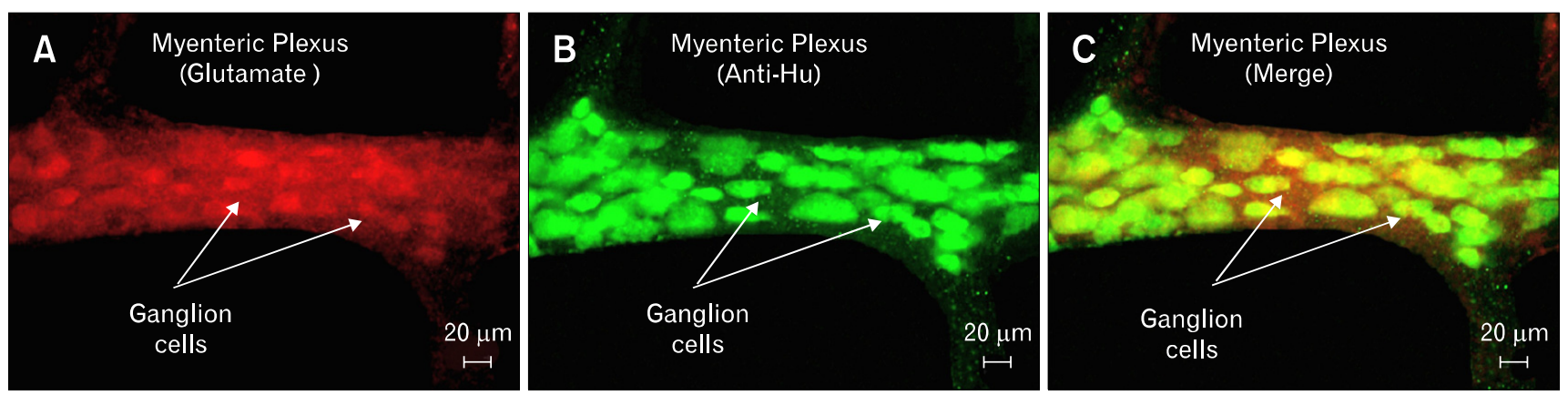

Figure 3. Proportion of neurons expressing glutamate immunoreactivity (IR) in whole-mount preparations of the myenteric plexus was determined by double-labeling glutamate and anti-human neuronal protein $\mathrm{HuC} / \mathrm{HuD}($ anti-Hu) in guinea pig small intestine. IR for the neuron-specific RNA binding protein, $\mathrm{Hu}$, was used to assess the total numbers of neurons in the preparations. (A) Expression of glutamate in a whole-mount preparation of the myenteric plexus. (B) Expression of anti-Hu-IR in the same whole-mount as A. (C) Digital merger of A and B revealed co-expression of glutamate-IR and anti-Hu-IR in $57.6 \%$ of the myenteric ganglion cells overall.
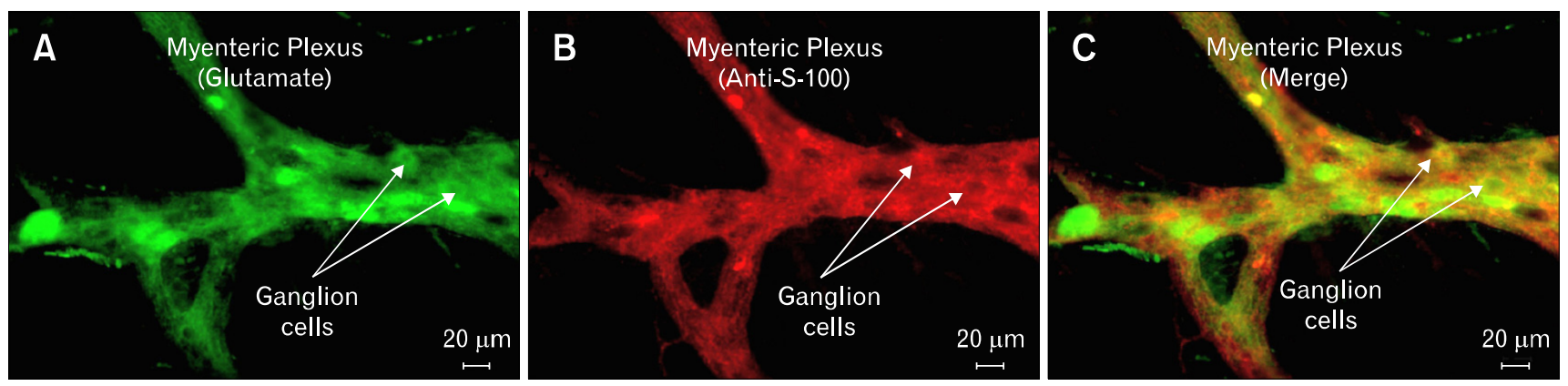

Figure 4. Proportion of glial cells expressing glutamate-immunoreactivity (IR) in whole-mount preparations of the myenteric plexus was determined by double-labeling glutamate and anti-S-100 protein in guinea pig small intestine. IR for S-100 protein was used to assess the population of glial cells in the preparations. (A) Expression of glutamate in a whole-mount preparation of the myenteric plexus. (B) Expression of anti-S-100 protein-IR in the same whole-mount as A. (C) Digital merger of A and B revealed absence of expression of glutamate-IR in enteric glia. 

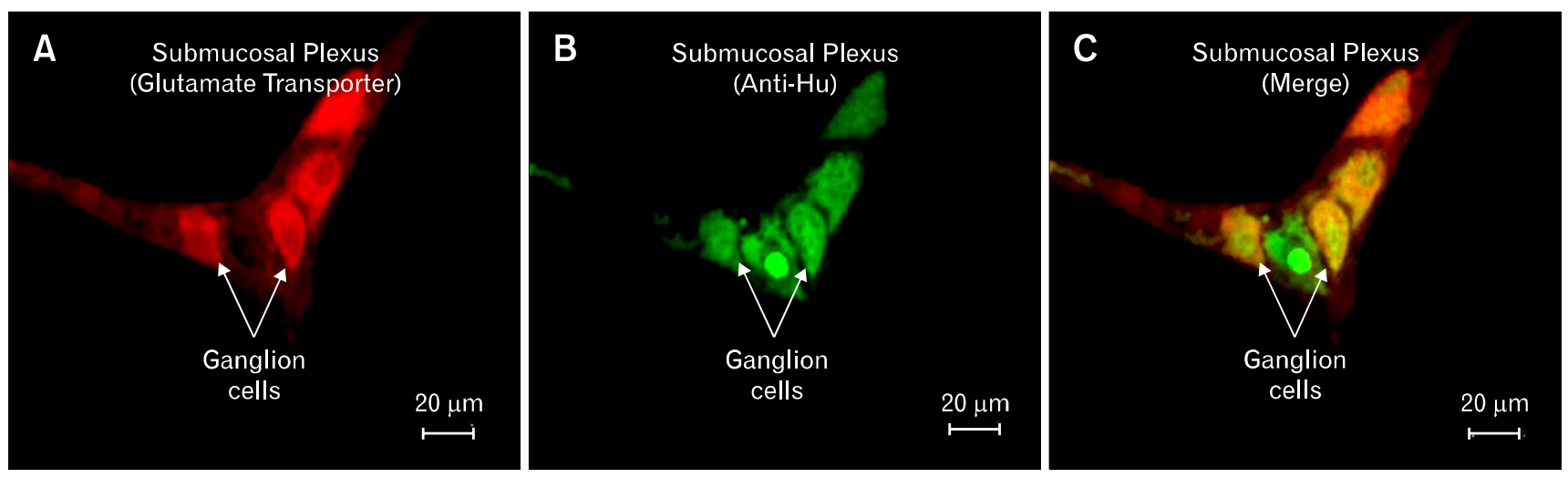

Figure 5. Proportion of neurons expressing immunoreactivity (IR) for the EAAC-1 glutamate transporter in whole-mount preparations of the submucosal plexus was determined by double-labeling EAAC-1 and anti-human neuronal protein $\mathrm{HuC} / \mathrm{HuD}$ (anti-Hu) in guinea pig small intestine. IR for the neuron-specific RNA binding protein, $\mathrm{Hu}$, was used to assess the total numbers of neurons in the preparations. (A) Expression of EAAC-1-IR in a whole-mount preparation of the submucosal plexus. (B) Expression of anti-Hu-IR in the same whole-mount as A. (C) Digital merger of $\mathrm{A}$ and $\mathrm{B}$ revealed coexpression of EAAC-1-IR and anti-Hu-IR in $42.7 \%$ of the submucosal ganglion cells overall.
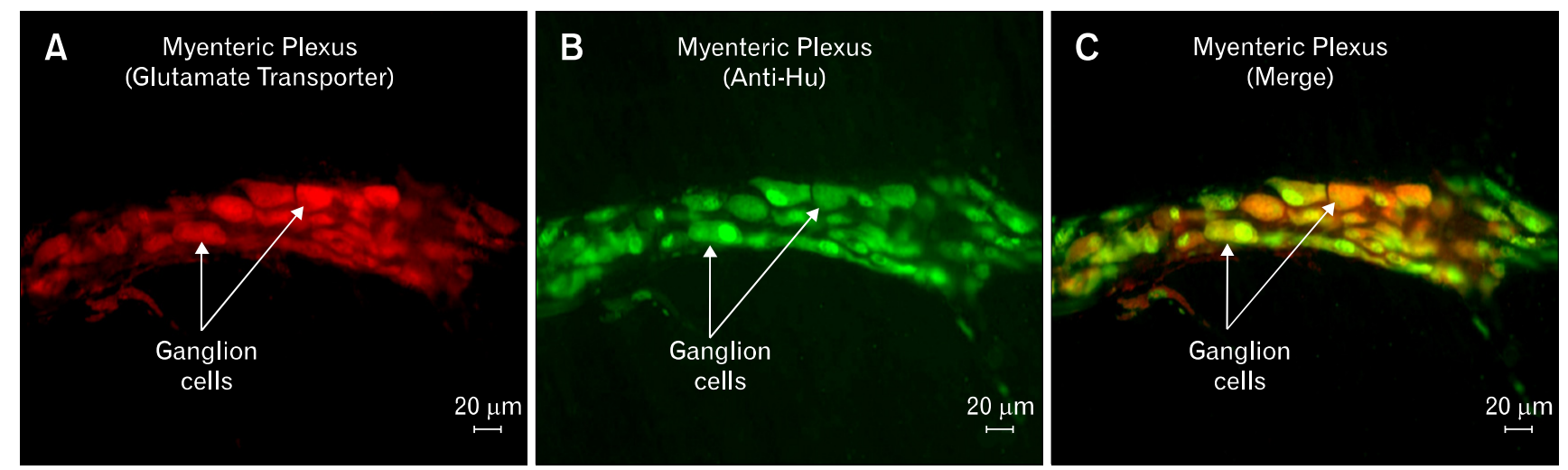

Figure 6. Proportion of neurons expressing immunoreactivity (IR) for the EAAC-1 glutamate transporter in whole-mount preparations of the myenteric plexus was determined by double-labeling EAAC-1 and anti-human neuronal protein $\mathrm{HuC} / \mathrm{HuD}$ (anti-Hu) in guinea pig small intestine. IR for the neuron-specific RNA binding protein, $\mathrm{Hu}$, was used to assess the total numbers of neurons in the preparations. (A) Expression of EAAC-1-IR in a whole-mount preparation of the myenteric plexus. (B) Expression of anti-Hu-IR in the same whole-mount as A. (C) Digital merger of $\mathrm{A}$ and $\mathrm{B}$ revealed co-expression of EAAC-1-IR and anti-Hu-IR in $53.4 \%$ of the myenteric ganglion cells overall.

mate transporter was found not to be co-expressed with immunoreactivity for S-100 protein in 6 preparations from the submucosal plexus of 4 guinea pigs (Fig. 7) and 6 myenteric plexus preparations from the same 4 guinea pigs.

\section{Electrophysiology}

We applied ACPD (土-trans-ACPD), which is a selective agonist for both group I and group II mGlu receptors including subtypes mGluR1-5, to neurons in guinea pig myenteric and submucosal plexus preparations. ${ }^{13}$ ACPD had no significant depolarizing action on the membrane potential and did not elevate neuronal excitability in 28 neurons distributed among the 2 kinds of preparations. We also applied NMDA, which is the prototypic agonist for glutamatergic ionotropic receptors in the brain, to the same 28 neurons in preparations from the 2 divisions of the guinea pig ENS and found no significant excitatory action. ${ }^{14}$

Figure 8 compares lack of effect of L-glutamate, ACPD and AMPA with excitatory actions of MRS2365 and substance $\mathrm{P}$ on neuronal excitability and neurotransmission for slow synaptic excitation (excitatory postsynaptic potential [EPSP]) in a secretomotor neuron in the submucosal plexus of guinea pig small intestine. MRS2365, a $\mathrm{P} 2 \mathrm{Y}_{1}$ purinergic receptor agonist, and substance $\mathrm{P}$ are slow EPSP mimetics in the ENS. ${ }^{15,16}$ The presence of the glutamatergic agonists in the bathing medium did not 

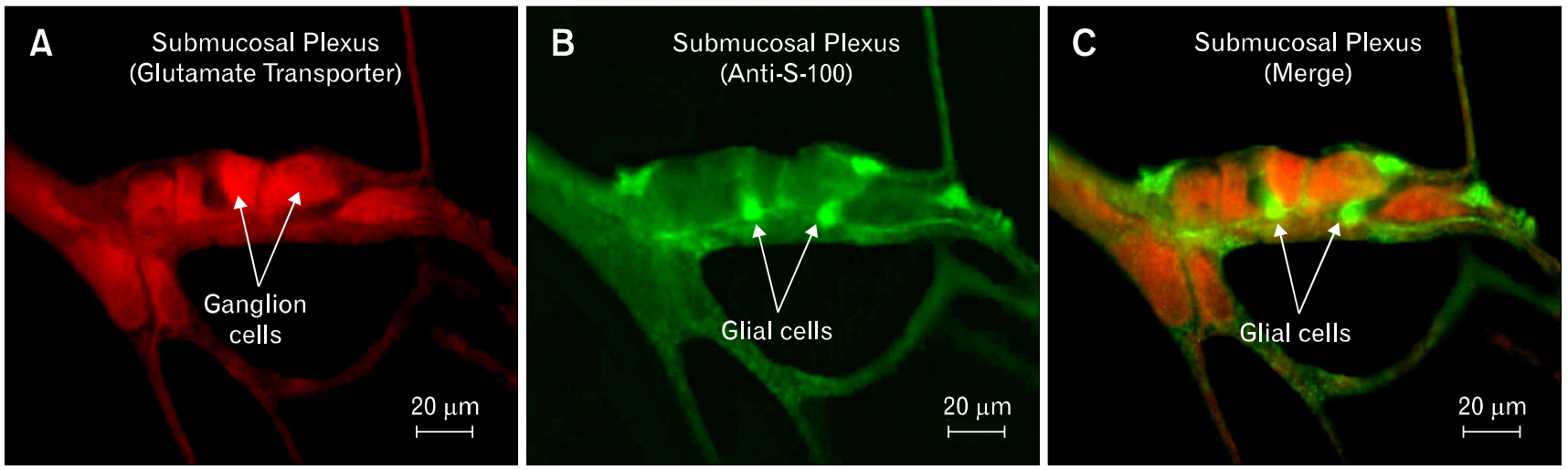

Figure 7. Proportion of glial cells expressing immunoreactivity (IR) for the EAAC-1 glutamate transporter in whole-mount preparations of the submucosal plexus was determined by double-labeling EAAC-1 and S-100 protein-IR in guinea pig small intestine. IR for the glial cell marker, S-100-protein, was used to assess the numbers of glial cells in the preparations. (A) Expression of EAAC-1-IR in a whole-mount preparation of the submucosal plexus. (B) Expression of S-100 protein-IR in the same whole-mount as A. (C) Digital merger of A and B. IR for the EAAC-1 glutamate transporter was co-expressed with S-100 protein-IR in the submucosal or myenteric plexus.

A

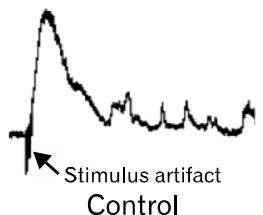

D

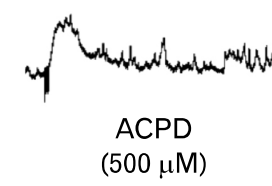

B

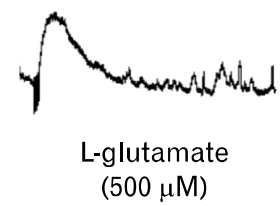

E

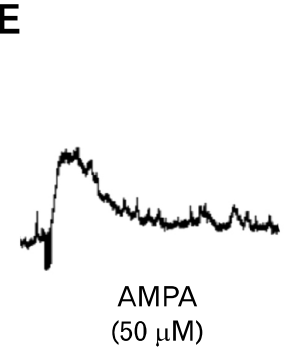

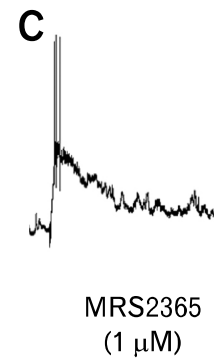

$\mathbf{F}$

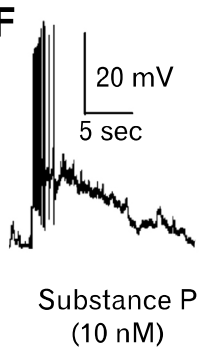

Figure 8. Absence of stimulatory action of glutamatergic receptor agonists on stimulus-evoked slow excitatory postsynaptic potentials (slow EPSP) in neurons of the guinea pig small intestinal submucosal plexus and stimulatory effect of 2 known slow EPSP neurotransmitters, ATP and substance P. ${ }^{1,2}$ (A) Control stimulus-evoked slow EPSP. (B) Lack of stimulatory action of L-glutamate on the slow EPSP. (C) Stimulatory action of the purinergic $\mathrm{P} 2 \mathrm{Y}_{1}$ receptor agonist, MS2365. (D) Lack of stimulatory action of the metabotropic glutamate receptor agonist, aminocyclopentane-1,3-dicarboxylic acid (ACPD). (E) Lack of stimulatory action of the specific glutamatergic receptor agonist, a-amino-3-hydroxy-5-methyl-4-isoxazole propionic acid (AMPA). (F) Stimulatory action of substance $\mathrm{P}$. Stimulus parameters were $5 \mathrm{~Hz}$ for 3 seconds.

change the latency for the response, the rate of rise of the slowly-activating membrane depolarization or excitability reflected by action potential discharge when compared with the slow EPSP-like actions of MRS2365 or substance P. Figure 9 presents quantitative data for the actions of glutamatergic agonists on slow EPSPs compared with the action of substance $\mathrm{P}$ and MRS2365. Figure 10 contains quantitative data for the actions of glutamatergic agonists on resting membrane potentials of S-type and $\mathrm{AH}$-type neurons in the myenteric and submucosal plexuses of the guinea pig small intestine.

\section{Mucosal Secretion}

Application of L-glutamate, in the serosal side compartment of the Ussing chambers, evoked increases in Isc with an $\mathrm{EC}_{50}$ of $370 \pm 21.6 \mu \mathrm{M}$ for 12 guinea pig preparations (Fig. 11). Application in the mucosal compartment of the chamber evoked increases in Isc with an $\mathrm{EC}_{50}$ of $291 \pm 19.0 \mu \mathrm{M}$ for 11 preparations (Fig. 11). Maximal concentrations of $500 \mu \mathrm{M} \mathrm{L}$-glutamate, based on the $\mathrm{EC}_{50}$ values for its stimulation of Isc, were used for pharmacological analysis of the action of L-glutamate (Fig. 12). Application of ACPD, which is an agonist for both group I and group II mGlu receptors, had no effect on Isc when applied on the serosal or mucosal side of the preparations (Fig. 12). Presence of the glutamate transport blocker, TBOA, reversed glutamate-evoked stimulation of Isc. The chloride secretory responses to L-glutamate were converted to chloride absorption in the presence of TBOA (Fig. 12). Blockade of secretomotor neuronal excitability by tetrodotoxin (TTX) reduced L-glutamate-evoked secretory responses by small, but significant incre- 
A

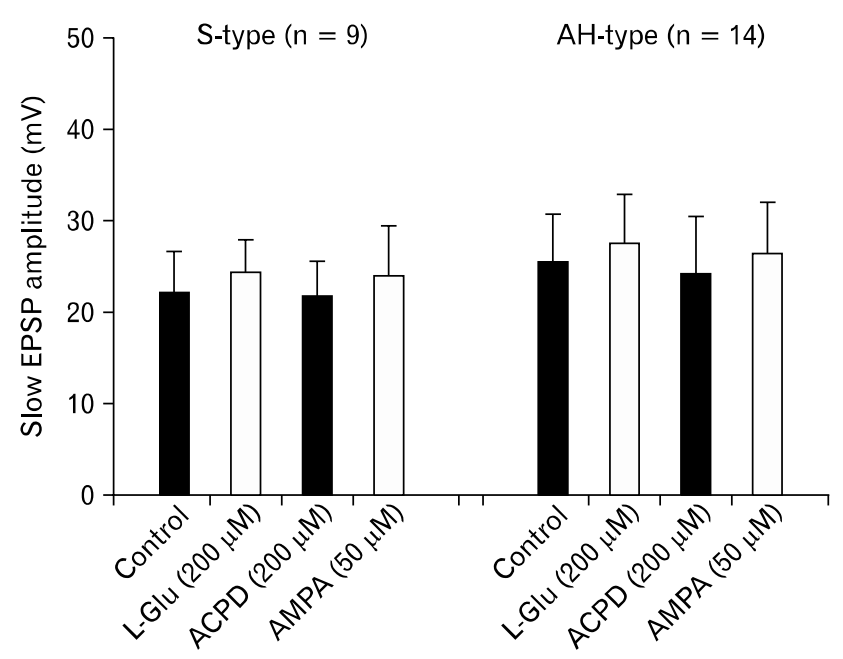

B Submucosal plexus

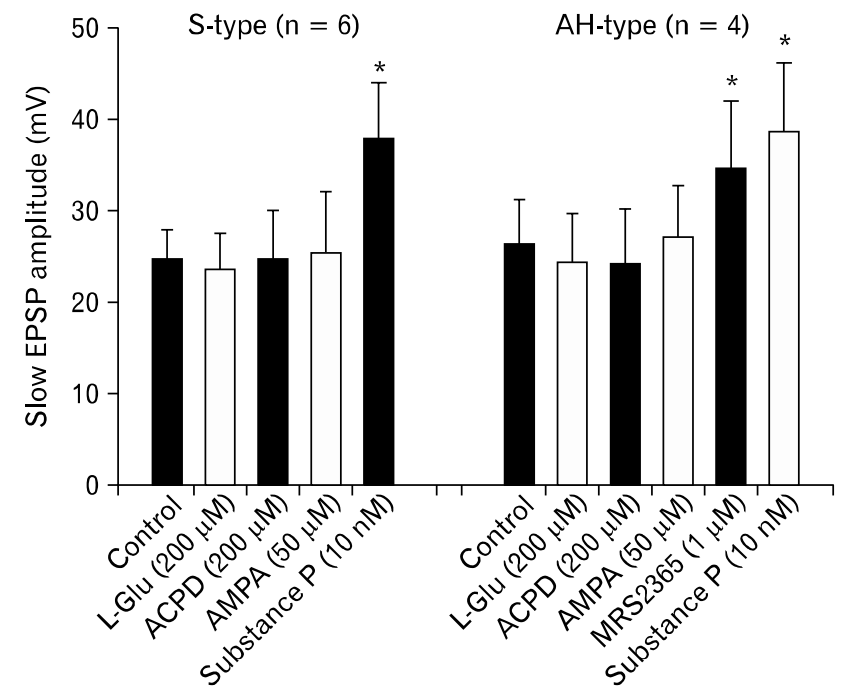

Figure 9. Quantitative data for absence of stimulatory action of glutamatergic receptor agonists on amplitude of stimulus-evoked slow excitatory postsynaptic potentials (slow EPSP) in neurons of the guinea pig small intestinal submucosal and myenteric plexuses as compared with excitatory actions of 2 known slow EPSP neurotransmitters in the enteric nervous system, ATP and substance P. (A) Quantitative data for action of glutamatergic receptor agonists on neurons with S- or AH-type electrophysiological behavior in guinea pig myenteric plexus. ${ }^{1,2}$ (B) Quantitative data for action of glutamatergic receptor agonists and slow EPSP mimetics, MRS2365 and substance $\mathrm{P}$ on neurons in guinea pig submucosal plexus. ${ }^{*} P<0.05$ relative to control, $\mathrm{n}=28$ neurons from a minimum of 3 guinea pigs. L-Glu, L-glutamate.

A

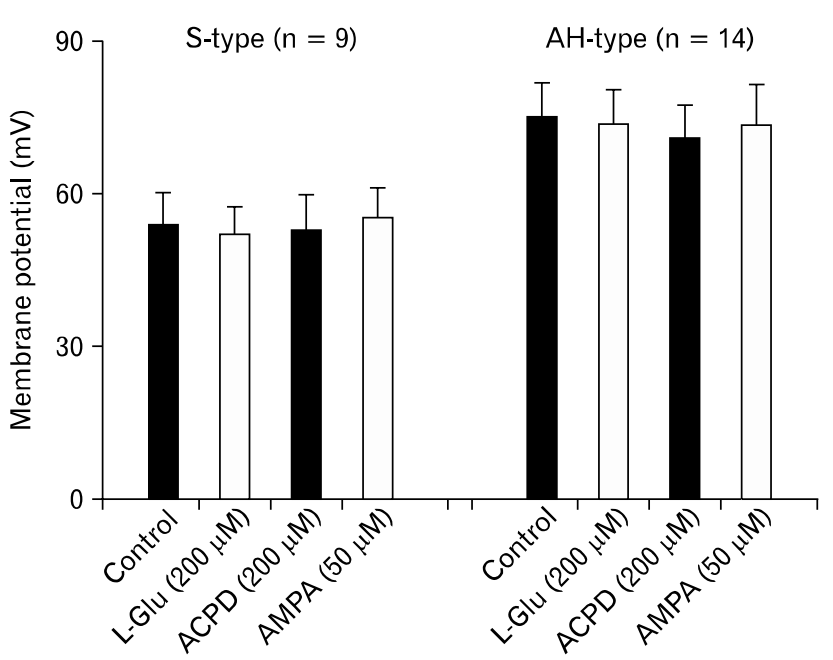

B

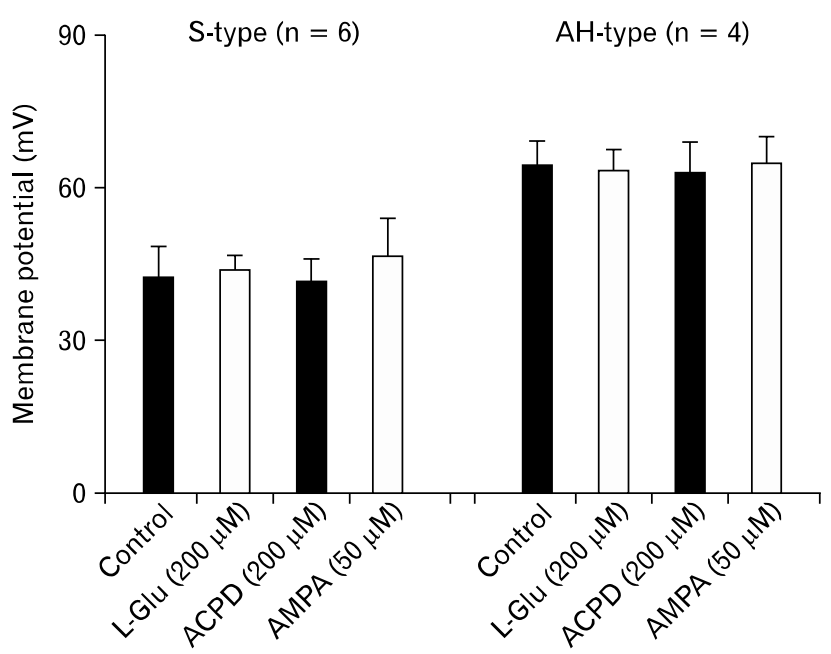

Figure 10. Quantitative data for lack of effect of glutamatergic receptor agonists on the resting membrane potential in neurons of the guinea pig small intestinal submucosal and myenteric plexuses. (A) Quantitative data for action of glutamatergic receptor agonists on membrane potential in neurons with S- or AH-type electrophysiological behavior in guinea pig myenteric plexus. ${ }^{1,2}$ (B) Quantitative data for action of glutamatergic receptor agonists on membrane potential in neurons with $\mathrm{S}$ - or AH-type electrophysiological behavior in guinea pig submucosal plexus. $\mathrm{n}=$ numbers of neurons from a minimum of 3 guinea pigs.

ments (Fig. 12). MCPG is a non-selective antagonist at group I and group II metabotropic glutamatergic receptors. ${ }^{17}$ Presence of $\mathrm{MCPG}$, in the bathing solution, did not alter stimulation of Isc by L-glutamate (Fig. 12). (S)-4-CPG, which is also a competitive antagonist at group I metabotropic glutamatergic receptors, like MCPG, had no effect on stimulation of Isc by 
L-glutamate (Fig. 12). ${ }^{17}$

In view of the above results, which suggested absence of expression of excitatory metabotropic glutamatergic receptors by secretomotor neurons in the guinea pig submucosal ENS, we

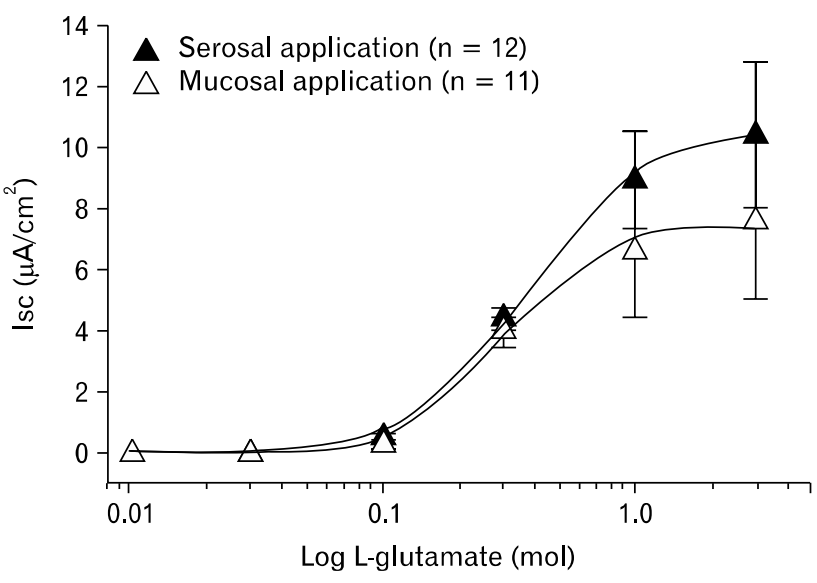

Figure 11. Concentration-response relations for stimulation of Isc by L-glutamate. $\mathrm{EC}_{50}=370 \pm 21.6 \mu \mathrm{M}$ for serosal side application; $\mathrm{EC}_{50}$ $=291 \pm 19.0 \mu \mathrm{M}$ for mucosal side application.

A

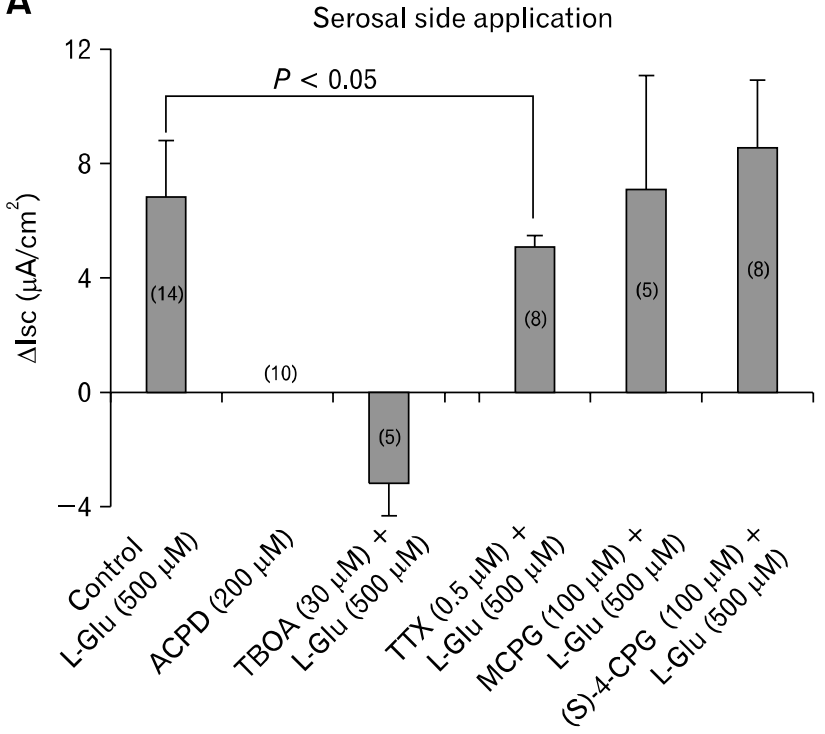

tested multiple selective agonists for glutamatergic action of this nature on mucosal secretion in human and guinea pig small intestine (Fig. 13). Aside from L-glutamate, the following agonists were analyzed: (1) (1S,3R)-ACPD, an agonist at mGluR1, mGluR2, mGluR5 and mGluR6; (2) ACPD; (3) CHPG Sodium Salt, a selective mGluR5 agonist; and (4) carbachol, which is a muscarinic receptor agonist that acts directly on the secretory epithelium to stimulate chloride secretion. ${ }^{7,18,19}$ Neither of the $\mathrm{mGluR}$ agonists stimulated mucosal chloride secretion relative to vehicle or to the secretory action of carbachol, which served as an indicator of the viability of the preparations.

\section{Musculature Contractility}

Strips of the muscularis externa, dissected from the longitudinal and circular axes of guinea pig and human small intestine with the myenteric plexus intact, generated spontaneous-rhythmic contractile activity (Fig. 14). We measured the amplitude of each spontaneously-occurring contraction over a specified time period and used the mean amplitude as a control for any changes evoked by application of L-glutamate or ACPD, which is a se-

B

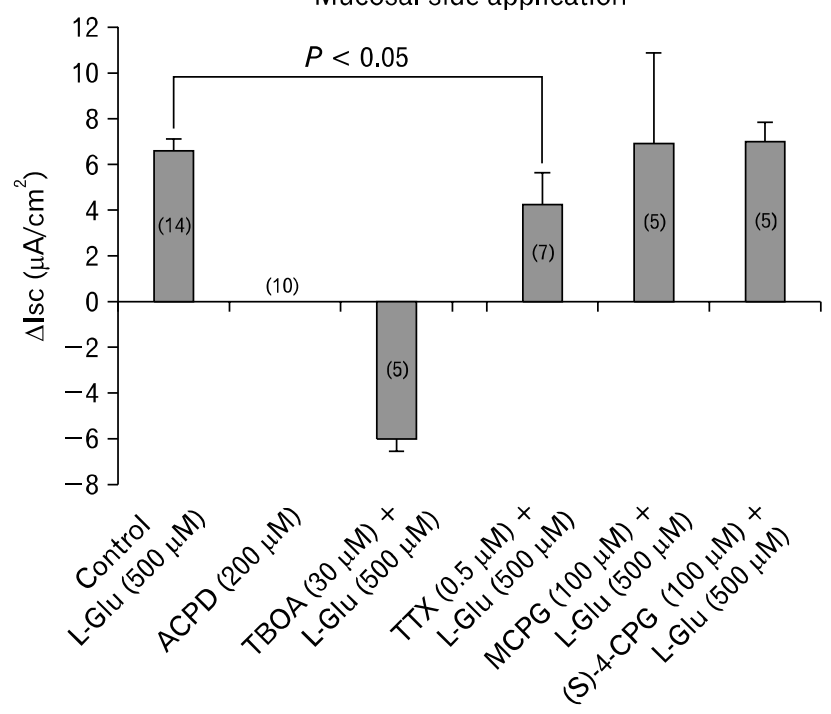

Figure 12. Glutamate secretory pharmacology in guinea pig small intestine. (A) Effects of glutamate agonists, antagonists and inhibitors of mucosal glutamate transport when applied in the Ussing chamber compartment bathing the serosal side of the preparations. (B) Same as for A except with application of the pharmacological agents in the Ussing chamber compartment bathing the mucosal side of the preparations. L-glutamate (L-Glu, 500 $\mu \mathrm{M})$ stimulated mucosal chloride secretion reflected by increased Isc in the electrically-positive direction when applied to the serosa or mucosa. The selective metabotropic glutamate (mGlu) I receptor agonist aminocyclopentane-1,3-dicarboxylic acid (ACPD, $200 \mu \mathrm{M})$ did not stimulate any increase in short-circuit current (Isc). The glutamate transporter inhibitor, 3S)-3-[[3-[[4-(Trifluoromethyl)benzoyl]amino] phenyl] methoxy]-L-aspartic acid (TBOA), suppressed glutamate-evoked Isc and converted the short-circuit to electrically-negative values indicative of net absorption of chloride. Tetrodotoxin (TTX) suppressed glutamate-evoked increases in Isc. Neither the non-selective mGlu I/II receptor antagonist, (RS)- $\alpha$-Methyl4-carboxyphenylglycine disodium salt (MCPG), nor the selective mGlu I $\alpha$ antagonist, (S)-4-Carboxyphenylglycine (CPG) suppressed stimulation of Isc by glutamate. Numbers of preparations appear in parentheses. 
A

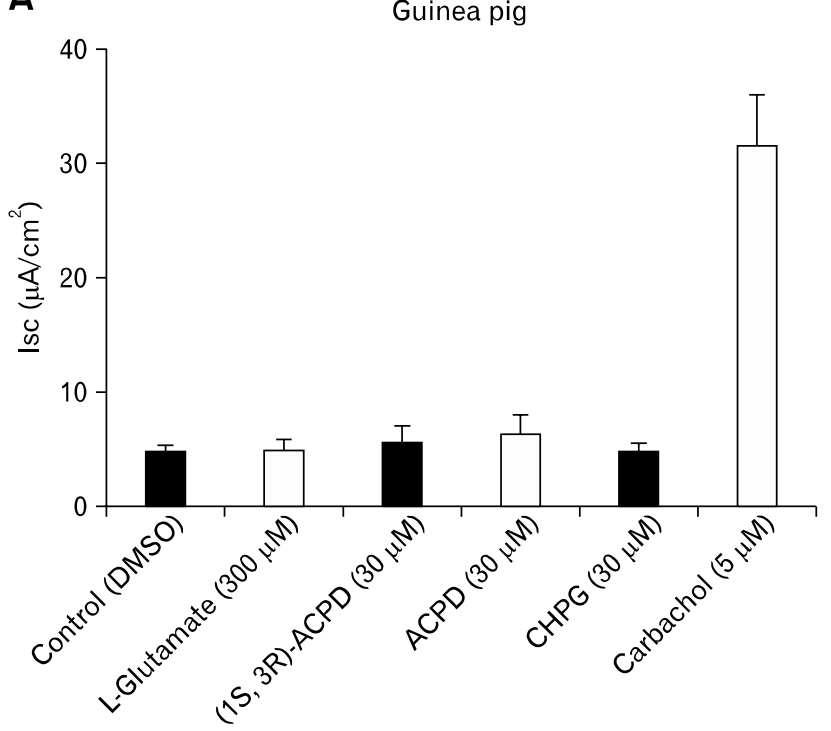

B

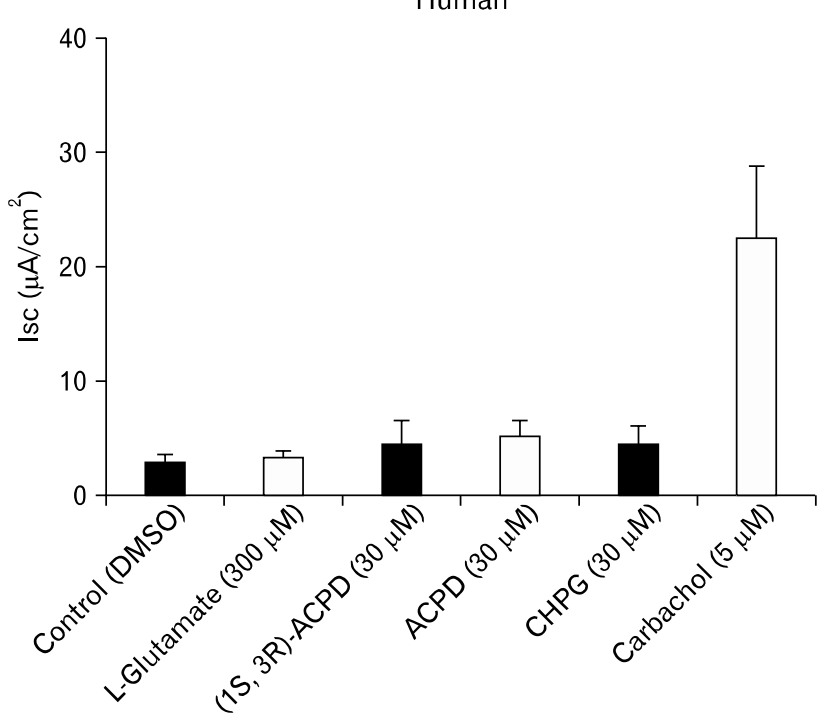

Figure 13. Action of L-glutamate and selective metabotropic glutamatergic receptor agonists on secretion of chloride (short-circuit current [Isc]) in guinea pig and human small intestinal preparations in Ussing flux chambers. Dimethyl sulfoxide (DMSO) was the vehicle for some agents. Carbachol, an agonist at muscarinic receptors, stimulated secretion as an indicator of the viability of the preparations. None of the metabotropic glutamate receptors agonists stimulated mucosal chloride secretion relative to vehicle or to the secretory action of carbachol. Data represent preparations from 8 guinea pigs and 8 human gastric bypass surgeries.

lective agonist for both group I and group II mGlu receptors including subtypes mGluR1-5 mentioned earlier. ${ }^{13}$

Neither L-glutamate nor ACPD changed the mean amplitude of spontaneously occurring contractions in circular or longitudinal strips of intestinal wall from either guinea pig or human small intestinal preparations (Fig. 14). Exposure to L-glutamate or ACPD did not change the frequency at which the spontaneously occurring contractions occurred in either longitudinal or circular strips of intestinal wall from guinea pig or human small intestine (data not shown).

\section{Discussion}

When bovine serum albumen, which serves as a model dietary protein, is infused in the small intestine of human subjects, digestion elevates intraluminal concentrations of glutamate to values as high as $7.3 \pm 2.17 \mu \mathrm{M} / \mathrm{mL} .{ }^{20}$ Concentrations in the blood, leaving the intestine in the portal circulation, are much lower mainly because L-glutamate is oxidized in epithelial cells during its transport from the lumen. ${ }^{21}$ Some of the dietarily-supplied glutamate, which escapes metabolic conversions in mucosal epithelial cells, most likely reaches the ENS embedded inside the intestinal wall.

The ENS is an independent integrative nervous system with many properties that mimic the CNS and inspires comparison of glutamatergic signaling in the minibrain-in-the-gut with the CNS brain. ${ }^{22}$ In the CNS brain, glutamate is compartmentalized in high concentrations inside neurons and low concentrations in the extraneuronal milieu. This distribution rigidly controls its availability for release as an excitatory neurotransmitter. ${ }^{23}$ Bloodborne glutamate does not enter the CNS because the blood-brain barrier is virtually impermeable to glutamate. ${ }^{24}$ Glutamate in CNS neurons is synthesized locally from glutamine by the action of phosphate-activated glutaminase. ${ }^{25}$

In view of the fact that the ENS is exposed to glutamate directly, we aimed to address the dogma that the cellular neurophysiology for glutamate in the ENS recapitulates its functional role as an excitatory neurotransmitter in the CNS. This was done by addressing the following: (1) Does application of glutamate excite ENS neurons (i.e., depolarize the membrane potential and evoke action potential discharge)? (2) Does application of glutamate stimulate firing of ENS musculomotor neurons that becomes evident as stimulation of muscle contractile amplitude? (3) Does exposure to glutamate stimulate firing of ENS secretomotor neurons that becomes evident as enhanced mucosal secretion? Moreover, we used immunohistochemical methods to clarify if glutamate is sequestered in ENS neurons and glia in association with expression of glutamate transporters in a comparative manner with the CNS. 


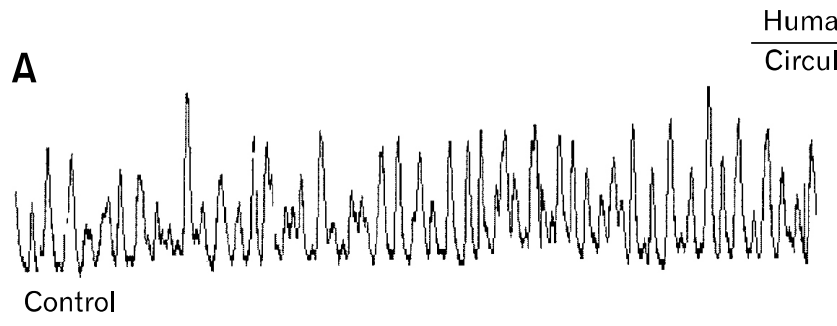

Human jejunum

A

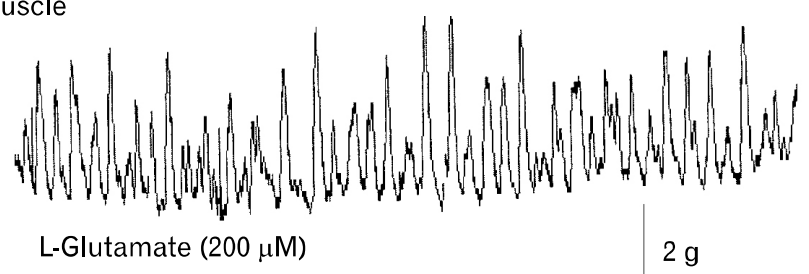

B

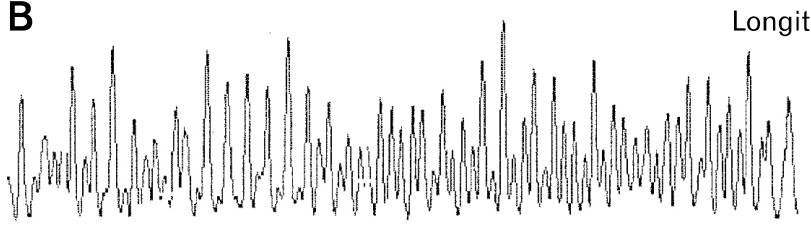

Control

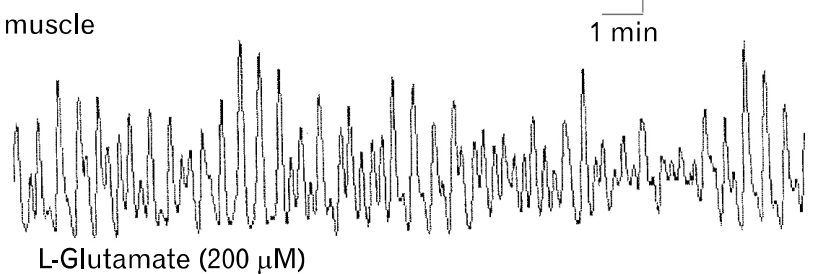

C
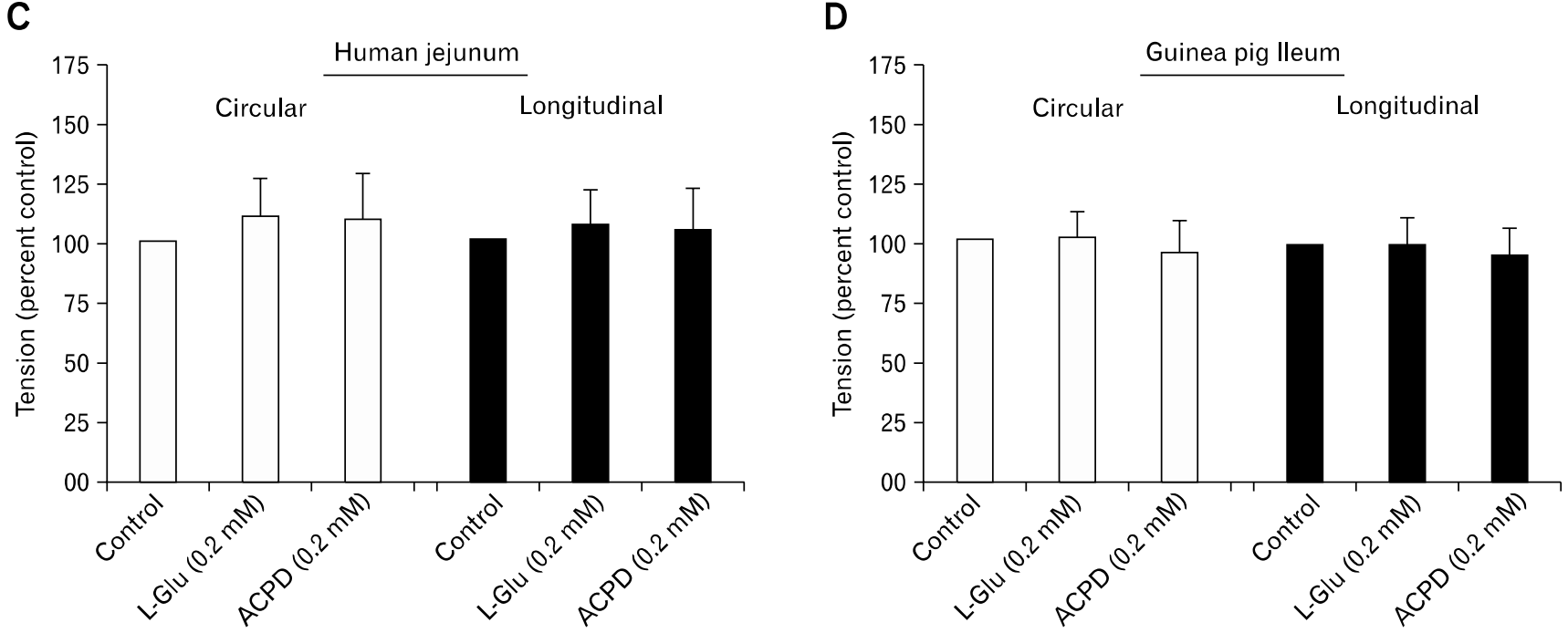

Figure 14. Actions of L-glutamate (L-Glu) on contractile activity of strips of intestinal wall removed from the longitudinal or circular axis of human jejunum and guinea pig ileum. (A) Action of L-Glu on circular strips. (B) Action of L-Glu on longitudinal strips. (C) Action of L-Glu and the metabotropic glutamate (mGlu) I receptor agonist, aminocyclopentane-1,3-dicarboxylic acid (ACPD), on contractile tension in circular and longitudinal muscle strips from human jejunum. (D) Action of L-Glu and the mGlu I receptor agonist, ACPD, on contractile tension in circular and longitudinal muscle strips from guinea pig ileum. Data represent preparations from 12 guinea pigs and 8 human gastric bypass surgeries.

As in CNS neurons, a majority, but not all, ENS neurons expressed glutamate-IR indicative of glutamate sequestration. Unlike CNS astrocytes, ENS glial cells did not appear to sequester glutamate. As is the case for CNS neurons, ENS neurons express the EAAC-1 glutamate transporter. On the other hand, glial cells in the ENS appear to differ from CNS astrocytes by not expressing immunoreactivity for the EAAC-1 transporter.

Expression of glutamate-IR in ENS neurons might reflect extraction of glutamate by neuronal transporters as it passes on route to the hepatic portal circulation. On the other hand, the glutamate-IR might be the result of glutamate synthesis in the neurons themselves. Both mechanisms are a possibility. However, unlike for CNS neurons, little is known about glutamate synthesis in single ENS neurons. Observations, which suggest that the interior of the ENS might be excluded from glutamate entry by a functional barrier, would suggest that synthesis accounts for the glutamate-IR expressed in the ENS neurons. Blood vessels do not enter the ENS ganglia in guinea pigs and a blood ganglion barrier analogous to the blood-brain barrier has been demonstrated for the myenteric plexus. ${ }^{26,27}$ Nevertheless, the barrier has been demonstrated only for macromolecules (i.e., labeled albumin or horseradish peroxidase).

In contrast to earlier reports, we found no significant electrophysiological effects of exposure of ENS neurons to L-glutamate or 
to ionotropic or metabotropic glutamatergic receptor agonists. ${ }^{28-31}$ Our tentative conclusion is that glutamate neuropharmacology for the ENS differs significantly from that for the CNS. Whereas, the brain synthesizes and compartmentalizes glutamate and uses it as a key excitatory neurotransmitter; we found little evidence that it is a neurotransmitter in the ENS. Apparently, neurons in the ENS do not express the receptors necessary for activation by the glutamate that escapes metabolism by the mucosal enterocytes as it passes the neurons on route to the hepatic portal circulation.

Published data for influence of glutamate on intestinal mucosal chloride secretion is sparse. A single paper reported that L-asparagine, an amino acid with similar structure to L-glutamate, stimulated chloride secretion in concentration-dependent manner and neural blockade with TTX suppressed the L-asparagine evoked secretion in piglets. ${ }^{32}$ Our results for L-glutamate are reminiscent of the data in this paper. We found that TTX suppressed L-glutamate-evoked increases in Isc, but by only about $33 \%$ of the response to L-glutamate alone. A much larger component was non-neurally mediated and related to enterocyte transport. This component most likely reflected electrogenic chloride movement coupled with basolateral sodium-dependent glutamate transport, because blockade of amino acid transporters reversed Isc from glutamate-evoked chloride secretion to chloride absorption. ${ }^{33}$

Aside from the minor suppression of glutamate-evoked chloride secretion by TTX, we found no other evidence that L-glutamate-evoked secretion was mediated by binding to excitatory glutamatergic receptors on ENS secretomotor neurons. This was magnified by failure of selective receptor agonists to mimic stimulation of chloride secretion by L-glutamate and failure of glutamatergic receptor antagonists to suppress stimulation of chloride secretion by L-glutamate.

The TTX effect on L-glutamate-evoked secretion might reflect blockade of conduction in intramural spinal and/or vagal afferents. Collaterals from intramural vagal and spinal afferents are known to innervate ENS neurons and evoke reflexes analogous to axonal reflexes underlying the "triple response" to irritation in the skin. Some of the evidence for this is finding that electrical stimulation of spinal afferents as they enter the intestine in the mesentery evokes excitatory postsynaptic potentials in neurons in the myenteric plexus. ${ }^{34}$ Terminals of the same afferents fire during exposure to amino acids, including L-glutamate. ${ }^{35-37}$ When the afferents are active, they release calcitonin gene-related peptide and substance $\mathrm{P}$, both of which are known stimulators of neurogenic chloride secretion. ${ }^{7}$ Therefore, TTX blockade of glu- tamate-evoked firing of the afferents might account for the minor reduction in glutamate stimulation of Isc that occurred in the presence TTX (Fig. 11). Glutamate-evoked firing of vagal afferents is mediated by release of 5 -hydroxytryptamine and its action at the 5-hydroxytryptamine 3 receptor subtype expressed on the afferent terminals rather than by any action at intramural neuronal glutamatergic receptors. ${ }^{37}$

This work was an alternative test of the hypothesis that glutamate in the small intestinal lumengains access and activates excitatory glutamatergic receptors expressed by ENS motor neurons. It investigated motility of the longitudinal and circular muscle coat of the guinea pig and human small bowel as an approach for identifying expression of glutamatergic receptors by musculomotor neurons in the ENS. If any stimulatory or inhibitory effects of glutamate on contractile activity were sensitive to neural blockade by TTX, it would suggest glutamatergic activation of excitatory or inhibitory musculomotor neurons in the myenteric plexus. Stimulation of excitatory musculomotor neurons would enhance contractile tension and increased discharge of inhibitory musculomotor neurons would suppress contractile activity.

We found no stimulation of contractile activity or inhibition of contractile activity by L-glutamate itself or commercial glutamate receptor agonists in guinea pig or human small intestine (Fig. 13). Neither the amplitude of ongoing contractions nor the frequency of contractions was altered. These results do not support the hypothesis that dietary glutamate in the small intestinal lumen gains access and activates excitatory glutamatergic receptors expressed by ENS musculomotor neurons.

\section{Conclusion}

In view of the ENS as a brain-in-the-gut, exciting discoveries for the neurobiology of excitatory glutamatergic neurotransmission in the CNS brain justified enthusiasm for the likelihood that results of investigation in the ENS would recapitulate the glutamatergic story for the CNS. This has proved not to be the case; although, transport and sequestration of glutamate in ENS neurons might serve to provide a substrate for synthesis of gamma-amino butyric acid, which is a putative neurotransmitter in the $\mathrm{ENS}^{38}$

\section{Acknowledgements}

The generous cooperation of bariatric surgeons, Bradley $\mathrm{J}$ 
Needleman and Dean J Mikami, in The Ohio State University Department of Surgery, made possible the acquisition of fresh segments of human jejunum that were discarded during Roux-En-Y gastric bypass surgeries.

\section{References}

1. Gershon MD. The Second Brain. New York: Harper-Collins 1998: 15-36.

2. Furness JB. The Enteric Nervous System. Oxford: Blackwell 2006: $1-266$.

3. Wood JD. Enteric nervous system: The brain-in-the-gut. New Jersey: Morgan \&Claypool Life Sciences 2011:1-157.

4. Monaghan DT, Bridges RJ, Cotman CW. The excitatory amino acid receptors: their classes, pharmacology, and distinct properties in the function of the central nervous system. Annu Rev Pharmacol Toxicol 1989;29:365-402.

5. Nakanishi S. Molecular diversity of glutamate receptors and implications for brain function. Science 1992;258:597-603.

6. Wood JD, Mayer CJ. Slow synaptic excitation mediated by serotonin in Auerbach's plexus. Nature 1978;276:836-837.

7. Cooke HJ, Reddix RA. Neural regulation of intestinal electrolyte transport. In: Johnson LR, ed. Physiology of the Gastrointestinal Track. Volume 2. 3rd ed. New York: Raven 1994:2083-2132.

8. Fang X, Hu HZ, Gao N, et al. Neurogenic secretion mediated by the purinergic $\mathrm{P}_{2} \mathrm{Y}_{1}$ receptor in guinea-pig small intestine. Eur J Pharmacol 2006;536:113-122.

9. Fei G, Raehal K, Liu S, et al. Lubiprostone reverses the inhibitory action of morphine on intestinal secretion in guinea pig and mouse. $\mathrm{J}$ Pharmacol Exp Ther 2010;334:333-340.

10. Fang X, Liu S, Wang XY, et al. Neurogastroenterology of tegaserod (HTF 919) in the submucosal division of the guinea-pig and human enteric nervous system. Neurogastroenterol Motil 2008;20:80-93.

11. Liu S, Ren W, Qu MH, et al. Differential actions of urocortins on neurons of the myenteric division of the enteric nervous system in guinea pig distal colon. Br J Pharmacol 2010;159:222-236.

12. Lin $\mathrm{Z}$, Gao N, Hu HZ, et al. Immunoreactivity of $\mathrm{Hu}$ proteins facilitates identification of myenteric neurones in guinea-pig small intestine. Neurogastroenterol Motil 2002;14:197-204.

13. Conti P, De Amici M, Bräuner-Osborne H, Madsen U, Toma L, De Micheli C. Synthesis and pharmacology of 3-hydroxy-delta2-isoxazoline-cyclopentane analogues of glutamic acid. Farmaco 2002; 57:889-895.

14. Watkins JC, Evans RH. Excitatory amino acid transmitters. Ann Rev Pharmacol Toxicol 1981;21:165-204.

15. Hu HZ, Gao N, Zhu MX, et al. Slow excitatory synaptic transmission mediated by $\mathrm{P}_{2} \mathrm{Y}_{1}$ receptors in the guinea-pig enteric nervous system. J Physiol 2003;550(Pt 2):493-504.

16. Morita K, North RA, Katayama Y. Evidence that substance $P$ is a neurotransmitter in the myenteric plexus. Nature 1980;287:151-152.

17. Eaton SA, Jane DE, Jones PL, et al. Competitive antagonism at metabotropic glutamate receptors by (S)-4-carboxyphenylglycine and (RS)-alpha-methyl-4-carboxyphenylglycine. Eur J Pharmacol 1993;
244:195-197.

18. Knopfel T, Kuhn R, Allgeier H. Metabotropic glutamate receptors: novel targets for drug development. J Med Chem 1995;38:14171426.

19. Bao WL, Williams AJ, Faden AI, Tortella FC. Selective mGluR5 receptor antagonist or agonist provides neuroprotection in a rat model of focal cerebral ischemia. Brain Res 2001;922:173-179.

20. Adibi SA, Mercer DW. Protein digestion in human intestine as reflected in luminal, mucosal, and plasma amino acid concentrations after meals. J Clin Invest 1973;52:1586-1594.

21. Blachier F, Boutry C, Bos C, Tomé D. Metabolism and functions of L-glutamate in the epithelial cells of the small and large intestines. Am J ClinNutr 2009;90:814S-821S.

22. Wood JD. Intrinsic neural control of intestinal motility. Ann Rev Physiol 1981;43:33-51.

23. Danbolt NC. Glutamate uptake. Prog Neurobiol 2001;65:1-105.

24. Hawkins RA. The blood-brain barrier and glutamate. Am J Clin Nutr 2009;90:867S-874S.

25. Ronzio RA, Rowe WB, Meister A. Studies on the mechanism of inhibition of glutamine synthetase by methionine sulfoximine. Biochemistry 1969;8:1066-1075.

26. Gabella G. Fine structure of the myenteric plexus in the guinea-pig ileum. J Anat 1972;111(Pt 1):69-97.

27. Gershon MD, Bursztajn S. Properties of the enteric nervous system: limitation of access of intravascular macromolecules to the myenteric plexus and muscularis externa. J Comp Neurol 1978;180:467-488.

28. Ren J, Hu HZ, Liu S, Xia Y, Wood JD. Glutamate receptors in the enteric nervous system: ionotropic or metabotropic? Neurogastroenterol Motil 2000;12:257-264.

29. Liu MT, Rothstein JD, Gershon MD, Kirchgessner AL. Glutamatergic enteric neurons. J Neurosci 1997;17:4764-4784.

30. Chen WP, Kirchgessner AL. Activation of group II mGlu receptors inhibits voltage-gated $\mathrm{Ca}^{2+}$ currents in myenteric neurons. Am J Physiol Gastrointest Liver Physiol 2002;283:G1282-G1289.

31. Kirchgessner AL, Liu MT, Alcantara F. Excitotoxicity in the enteric nervous system. J Neurosci 1997;17:8804-8816.

32. Rhoads JM, Argenzio RA, Chen W, Gomez GG. Asparagine stimulates piglet intestinal $\mathrm{Cl}$ - secretion by a mechanism requiring a submucosal glutamate receptor and nitric oxide. J Pharmacol Exp Ther 1995;274:404-412.

33. Kanai Y, Nussberger S, Romero MF, Boron WF, Hebert SC, Hediger MA. Electrogenic properties of the epithelial and neuronal high affinity glutamate transporter. J Biol Chem 1995;270:16561-16568.

34. Takaki M, Nakayama S. Effects of mesenteric nerve stimulation on the electrical activity of myenteric neurons in the guinea pig ileum. Brain Res 1988;442:351-353.

35. Jeanningros R. Vagal unitary responses to intestinal amino acid infusions in the anesthetized cat: a putative signal for protein induced satiety. Physiol Behav 1982;28:9-21.

36. Mei N. Intestinal chemosensitivity. Physiol Rev 1985;65:211-237.

37. Uneyama H, Niijima A, San Gabriel A, Torii K. Luminal amino acid sensing in the rat gastric mucosa. Am J Physiol Gastrointest Liver Physiol 2006;291:G1163-G1170.

38. Jessen KR. GABA and the enteric nervous system. A neurotransmitter function? Mol Cell Biochem 1981;38(Pt 1):69-76. 